\title{
Cliente Oculto: a Utilização da Pesquisa de Marketing para Avaliação da Qualidade dos Serviços em uma Rede de Confeitarias
}

\author{
Juliana C. Fernandes, Sarah B. Lopes \& Suilly F. Bueno
}

Na pesquisa de Cliente Oculto, os avaliadores observam a qualidade do serviço de uma empresa. Essa pesquisa foi realizada a fim de avaliar a qualidade da prestação de serviços de uma rede de confeitarias. Os itens do questionário foram divididos em blocos: aparência física, atendimento, fechamento de venda e experiência de compra. Para discussão dos resultados, foi determinado um índice de satisfação com quatro níveis: até $25 \%$ inaceitável, de 26 a 50\% aceitável, de 51 a $75 \%$ ideal e acima de $76 \%$ superação. No bloco experiência de compra, a média de satisfação geral no atendimento foi de $36 \%$, classificando a prestação do serviço como aceitável.

Palavras-chave: Satisfação; qualidade; serviços.

Mystery Shopping is a tool used to measure quality of services. The mystery shoppers evaluate anonymously the services offered by the establishment. This research was conducted to evaluate the quality of services in a confectionery company. The checklist items divided into groups: Physical Appearance, Customer Service, Closing and Shopping Experience. For discussion of the results, it was given a percentage satisfaction rate with four levels: up to $25 \%$ unacceptable, $26-50 \%$ acceptable, $51-75 \%$ ideal and above $76 \%$ overcoming. In Shopping Experience group, the average of overall satisfaction in service was $36 \%$, which classify the service as acceptable.

Keywords: Satisfaction; quality; services. 


\section{Introdução}

Atualmente, as empresas procuram ser mais competitivas no mercado. Com isso, a avaliação da qualidade dos serviços e do atendimento ao cliente é importante para atender às exigências dos consumidores. Assim, para essa avaliação, é necessário confrontar as expectativas dos clientes e a percepção sobre o serviço recebido ${ }^{1}$. Sendo, então, a consequência de um atendimento de excelência, a fidelização do cliente ${ }^{2}$.

Neste artigo, utilizou-se a técnica denominada Cliente Oculto, também conhecida como cliente/ consumidor misterioso. É uma das variáveis de pesquisa de marketing, a observacional, composta pelo registro do comportamento de pessoas, objetos e acontecimentos $^{3}$. A vantagem do Cliente Oculto reside no fato de ser possível observar o que realmente as pessoas fazem, ou seja, o pesquisador vê o que as pessoas fazem e não o que elas dizem fazer. Essa ferramenta é um indicador de como estão sendo realizadas as interações com os consumidores, sendo extremamente relevante devido ao momento de alta competitividade em que vivemos e à alta repercussão negativa que pode haver ${ }^{4}$.

A origem do estudo neste artigo sobre a técnica de Cliente Oculto na avaliação da qualidade dos serviços foi a expectativa de poder analisar a aplicabilidade da técnica, quantificar a satisfação dos clientes, podendose apontar melhorias. Assim, poderá elaborar estratégias para atingir a excelência no atendimento e um índice de satisfação superior às perspectivas.

Dessa forma, o presente artigo tem como objetivo demonstrar a aplicação da técnica de Cliente Oculto como forma de avaliação da qualidade em serviços de uma rede de lojas de produtos alimentícios do ramo de confeitaria, composta por 6 lojas, sendo 2 lojas próprias (Eng. Portela, Ana Shopping) e 4 franquias (Jaiara, Jundiaí, Alexânia e Caldas Novas).

\section{Métodos}

Para coleta dos dados referente à pesquisa de Cliente Oculto, foi elaborado um questionário com os itens a serem avaliados pelo cliente/avaliador oculto, sendo estruturado em quatro blocos:
1)Aparência Física - avaliação da apresentação pessoal dos funcionários, exposição dos produtos e a aparência física da loja.

2) Atendimento - avaliação do atendimento ao cliente na abordagem, cortesia, gentileza, demonstração e conhecimento dos produtos e procedimento de venda no geral.

3) Fechamento - avaliação do procedimento de fechamento da venda.

4) Experiência de Compra - avaliação geral da visita em relação à qualidade dos produtos adquiridos e satisfação no atendimento como um todo.

Nos blocos 1, 2 e 3 foram estabelecidas três alternativas de respostas objetivas para cada item, em que o avaliador assinala a resposta SIM para os itens em conformidade com a questão, NÃO para os itens não conformes e NA para os itens não avaliados ou não aplicáveis à loja avaliada. No bloco 4 , foram estabelecidas quatro alternativas de resposta em cada item, para avaliação geral da satisfação do consumidor em relação à experiência de compra: Superação, Ideal, Aceitável e Inaceitável.

Para análise dos dados obtidos na avaliação do Cliente Oculto, foram estabelecidos critérios de pontuação para as respostas assinaladas no questionário, a fim de se calcular a porcentagem de conformidade ao final de cada bloco e classificar o índice de satisfação do atendimento.

A cada item do questionário dos blocos 1,2 e 3, foram atribuídos pontos para as respostas afirmativas, de acordo com a importância de cada questão no padrão do atendimento. Esses pontos foram atribuídos, segundo os critérios informados pela empresa pesquisada, conforme Quadro 1.

Quadro 1: Escala de Pontuação - Blocos 1, 2 e 3

\begin{tabular}{|c|c|}
\hline \multicolumn{2}{|c|}{ ESCALA DE PONTUAÇÃo } \\
\hline 1 Ponto & Item pouco importante \\
\hline 2 Pontos & Item importante \\
\hline 3 Pontos & Item muito importante \\
\hline
\end{tabular}


No caso de respostas negativas, a pontuação atribuída ao item é igual a zero. Para as respostas NA, o item não recebe nenhuma pontuação e é desconsiderado para o cálculo da porcentagem do índice de satisfação.

$\mathrm{Na}$ análise do bloco 4 , há quatro tipos de respostas possíveis para cada item, de acordo com a satisfação do consumidor no atendimento, pontuadas, conforme mostra o Quadro 2.

Quadro 2: Escala de Pontuação - Bloco 4

\begin{tabular}{|c|c|}
\hline RESPOSTA & PONTUAÇÃo \\
\hline Superação & 4 Pontos \\
\hline Ideal & 3 Pontos \\
\hline Aceitável & 2 Pontos \\
\hline Inaceitável & 1 Ponto \\
\hline
\end{tabular}

A partir dos critérios de pontuação definidos acima, a pontuação individual de cada bloco, para cálculo da porcentagem de satisfação, ficou estabelecida, conforme Tabelas 1,2 e 3.

Tabela 1: Pontuação dos itens - Bloco 1

\begin{tabular}{|c|c|c|}
\hline ITEM & QUESTÃo & PONTOS \\
\hline 1.1 .1 & $\begin{array}{c}\text { A apresentação pessoal do atendente } \\
\text { está adequada? }\end{array}$ & 3 \\
\hline 1.1 .2 & $\begin{array}{c}\text { Na área interna da loja, móveis, } \\
\text { expositores e equipamentos estão em } \\
\text { boas condições de funcionamento, } \\
\text { conservação, higiene e limpeza? }\end{array}$ & 2 \\
\hline 1.1 .3 & $\begin{array}{c}\text { O balcão está bem abastecido, com } \\
\text { salgados médios/pequenos, tortas, } \\
\text { bolo gelado, trufas, bombons, } \\
\text { cupcake, tacinhas e docinhos? }\end{array}$ & 3 \\
\hline 1.1 .4 & $\begin{array}{c}\text { Todos os produtos expostos no balcão } \\
\text { contêm etiqueta de identificação com } \\
\text { data de manipulação e validade? }\end{array}$ & 2 \\
\hline \multirow{2}{*}{ TOTAL DE PONTOS DO BLOCO 1 } & $\mathbf{1 0}$ \\
\hline
\end{tabular}

Tabela 2: Pontuação dos itens - Bloco 2

\begin{tabular}{|c|c|c|}
\hline ITEM & QUESTÃO & PONTOS \\
\hline 2.1 .1 & $\begin{array}{l}\text { O atendente aborda o consumidor em } \\
\text { tempo adequado? }\end{array}$ & 3 \\
\hline 2.1 .2 & $\begin{array}{l}\text { O atendente faz uma saudação gentil } \\
\text { ao abordar o consumidor? }\end{array}$ & 3 \\
\hline 2.1 .3 & $\begin{array}{c}\text { O atendente faz algum tipo de } \\
\text { pergunta padrão ao iniciar o } \\
\text { atendimento? }\end{array}$ & 1 \\
\hline 2.1 .4 & $\begin{array}{l}\text { O atendente tem conhecimento para } \\
\text { argumentar com o cliente sobre os } \\
\text { produtos? }\end{array}$ & 3 \\
\hline 2.1 .5 & $\begin{array}{l}\text { O atendente oferece a demonstração } \\
\text { de algum produto para o consumidor? } \\
\text { (item sem pontuação, utilizado } \\
\text { apenas para informação) }\end{array}$ & 0 \\
\hline 2.1 .6 & $\begin{array}{l}\text { O atendente tem conhecimento para } \\
\text { orientar o consumidor sobre a rede } \\
\text { de lojas? }\end{array}$ & 2 \\
\hline 2.1 .7 & $\begin{array}{l}\text { O atendente separa os produtos } \\
\text { que você escolheu e os embala } \\
\text { corretamente? }\end{array}$ & 2 \\
\hline 2.1 .8 & $\begin{array}{l}\text { O atendente pergunta se você deseja } \\
\text { que os produtos sejam aquecidos, ou } \\
\text { os aquece prontamente? }\end{array}$ & 2 \\
\hline 2.1 .9 & $\begin{array}{c}\text { O atendente aquece os salgados por, } \\
\text { no mínimo, } 40 \text { segundos antes de } \\
\text { servir ao cliente? }\end{array}$ & 2 \\
\hline 2.1 .10 & $\begin{array}{l}\text { O atendente pergunta ao consumidor } \\
\text { se deseja algo mais ou alguma bebida } \\
\text { para acompanhar? }\end{array}$ & 2 \\
\hline 2.1 .11 & $\begin{array}{l}\text { O atendente pratica a venda adicional, } \\
\text { oferecendo ao cliente algum produto } \\
\text { adicional além do que ele foi } \\
\text { comprar? }\end{array}$ & 3 \\
\hline \multicolumn{2}{|c|}{ TOTAL DE PONTOS DO BLOCO 2} & 23 \\
\hline
\end{tabular}


Tabela 3: Pontuação dos itens- Bloco 3

\begin{tabular}{|c|c|c|}
\hline ITEM & QUESTÃO & PONTOS \\
\hline 3.1 .1 & $\begin{array}{l}\mathrm{O} \text { atendente entrega a comanda } \\
\text { com os produtos adquiridos para } \\
\text { pagamento? }\end{array}$ & 2 \\
\hline 3.1 .2 & $\begin{array}{l}\text { O atendente do caixa valida com o } \\
\text { consumidor os produtos que está } \\
\text { adquirindo, o valor total e a condição } \\
\text { de pagamento? }\end{array}$ & 2 \\
\hline 3.1 .3 & $\begin{array}{l}\text { O atendente do caixa entrega o } \\
\text { cupom fiscal de forma espontânea? }\end{array}$ & 2 \\
\hline 3.1 .4 & $\begin{array}{l}\text { Os atendentes (caixa e balcão) } \\
\text { valorizam o atendimento, despedem- } \\
\text { se e convidam o consumidor para } \\
\text { voltar novamente à loja? }\end{array}$ & 3 \\
\hline 3.1 .5 & $\begin{array}{l}\text { Os atendentes mantiveram a postura } \\
\text { prestativa e positiva no momento em } \\
\text { que esteve na loja? }\end{array}$ & 3 \\
\hline 3.1 .6 & $\begin{array}{l}\text { Durante o atendimento, os } \\
\text { atendentes que estavam atrás do } \\
\text { balcão mantiveram coordenação, } \\
\text { comunicação e cooperação com a } \\
\text { equipe? }\end{array}$ & 3 \\
\hline 3.1 .7 & $\begin{array}{l}\text { O atendente do caixa era o mesmo } \\
\text { atendente do balcão? (item sem } \\
\text { pontuação, utilizado apenas para } \\
\text { informação) }\end{array}$ & 0 \\
\hline \multicolumn{2}{|c|}{ TOTAL DE PONTOS DO BLOCO 3} & 15 \\
\hline
\end{tabular}

$\mathrm{Na}$ avaliação da Experiência de Compra, para cada tipo de resposta, foi atribuída uma pontuação diferente, conforme descrito nos critérios de pontuação. Sendo estabelecida como pontuação máxima para o bloco a soma dos pontos da resposta de maior valor, ou seja, a superação.

Neste bloco, foram avaliados três itens, como mostra a Tabela 4 .

Após a soma dos pontos obtidos ao final de cada bloco, pode-se calcular a porcentagem de satisfação no atendimento, onde se estipulou que $100 \%$ corresponde ao total máximo de pontos possíveis em cada bloco.

Foram definidos 4 níveis de satisfação no atendimento, conforme mostrado no Quadro 3.
Tabela 4: Pontuação dos itens - Bloco 4

\begin{tabular}{|c|c|}
\hline $\begin{array}{l}\text { ITEM 4.1. Em relação à qualidade dos produtos adquiridos } \\
\text { nessa visita: }\end{array}$ & Pontos \\
\hline $\begin{array}{l}\text { SUPERAÇÃO - Supera e surpreende as expectativas. Os } \\
\text { produtos apresentam aparência e sabor melhores que o esperado, } \\
\text { que destacam a empresa XX das outras lojas especializadas } \\
\text { em salgados, tortas e sobremesas. }\end{array}$ & 4 \\
\hline $\begin{array}{l}\text { IDEAL - Atende àquilo que era esperado. Os produtos } \\
\text { apresentam aparência e sabor esperados, como qualquer outra } \\
\text { loja especializada em salgados, tortas e sobremesas. }\end{array}$ & 3 \\
\hline $\begin{array}{l}\text { ACEITÁVEL-Atende parcialmente ao que era esperado } \\
\text { e requer melhorias em alguns aspectos. Os produtos } \\
\text { apresentam boa qualidade e sabor, mas deixam a desejar em } \\
\text { alguns aspectos, como temperatura, aparência, etc. }\end{array}$ & 2 \\
\hline $\begin{array}{l}\text { INACEITÁVEL - Não houve atendimento do que era } \\
\text { esperado e há necessidade de melhorias em vários aspectos. } \\
\text { Experiência foi desagradável. }\end{array}$ & 1 \\
\hline $\begin{array}{l}\text { ITEM 4.2. Pensando nessa visita, independentemente, de } \\
\text { qualquer outra experiência anterior com esta loja ou com essa } \\
\text { marca, como foi sua experiência de compra? }\end{array}$ & Pontos \\
\hline $\begin{array}{l}\text { SUPERAÇÃO - Supera e surpreende as expectativas. Tem } \\
\text { uma experiência memorável e marcante, é notório o carinho } \\
\text { prestado em cada contato. Tem vontade de voltar à loja com } \\
\text { frequência e tem grande admiração pela marca e loja. }\end{array}$ & 4 \\
\hline $\begin{array}{l}\text { IDEAL - Atende àquilo que era esperado. Tem uma boa } \\
\text { experiência como qualquer outra loja especializada em } \\
\text { salgados, tortas e sobremesas e percebe-se um atendimento } \\
\text { exclusivo e carinhoso. Tem vontade de voltar à loja } \\
\text { novamente. }\end{array}$ & 3 \\
\hline $\begin{array}{l}\text { ACEITÁVEL - Atende parcialmente ao que era esperado } \\
\text { e requer melhorias em alguns aspectos. Tem uma boa } \\
\text { experiência como qualquer outra loja especializada em } \\
\text { salgados, tortas e sobremesas e percebe-se um esforço para } \\
\text { que o atendimento seja agradável e carinhoso. Antes de voltar } \\
\text { a esta loja, visitaria outra loja XX para comparar. }\end{array}$ & 2 \\
\hline $\begin{array}{l}\text { INACEITÁVEL - Não houve atendimento do que era } \\
\text { esperado e há necessidade de melhorias em vários aspectos. } \\
\text { Experiência foi desagradável. Dificilmente, voltaria à loja, } \\
\text { prefiro conhecer um concorrente. }\end{array}$ & 1 \\
\hline $\begin{array}{l}\text { ITEM 4.3. Pensando nessa visita, independente de qualquer } \\
\text { outra experiência anterior com esta loja ou com essa marca, } \\
\text { você indicaria nossa loja a um amigo ou parente? }\end{array}$ & Pontos \\
\hline $\begin{array}{l}\text { SUPERAÇÃO - Sim, indicaria com toda certeza. O } \\
\text { atendimento é fantástico, as pessoas se preocupam com } \\
\text { o consumidor e dão toda atenção e carinho. Sempre têm } \\
\text { alguma novidade em produtos, promoção e/ou campanha. }\end{array}$ & 4 \\
\hline $\begin{array}{l}\text { IDEAL - Sim, indicaria. } \mathrm{O} \text { atendimento é diferenciado e } \\
\text { exclusivo, as pessoas têm carinho pelo consumidor. Sempre } \\
\text { tem alguma novidade. }\end{array}$ & 3 \\
\hline $\begin{array}{l}\text { ACEITÁVEL - Sim, indicaria, mas acabo comentando sobre } \\
\text { algo que não foi positivo. As pessoas se esforçam para que } \\
\text { o atendimento seja agradável e carinhoso. É uma loja como } \\
\text { qualquer outra loja especializada em chocolates finos. }\end{array}$ & 2 \\
\hline $\begin{array}{l}\text { INACEITÁVEL - Não indicaria. Informaria a meus } \\
\text { amigos e parentes sobre uma série de pontos negativos que } \\
\text { aconteceram quando estive na loja. O atendimento é ruim, } \\
\text { a vendedora sequer saiu de trás do balcão para atender. Não } \\
\text { fiquei sabendo sobre algum produto diferenciado, campanha } \\
\text { e/ou promoção. }\end{array}$ & 1 \\
\hline TOTAL MÁXIMO DE PONTOS DO BLOCO 4 & 12 \\
\hline
\end{tabular}


Quadro 3: Índice de Satisfação

\begin{tabular}{|c|c|}
\hline \multicolumn{2}{|c|}{ ÍNDICE DE SATISFAÇÃO } \\
\hline 0 a $25 \%$ & Inaceitável \\
\hline 26 a $50 \%$ & Aceitável \\
\hline 51 a $75 \%$ & Ideal \\
\hline 76 a $100 \%$ & Superação \\
\hline
\end{tabular}

\section{Resultados e Discussão}

No bloco de Aparência Física, foi possível avaliar que as lojas de Caldas Novas e Jaiara apresentaram os menores índices de satisfação, 30\% e 20\% respectivamente; as lojas de Alexânia, Ana Shopping, Eng. Portela e Jundiaí apresentaram $50 \%$ da satisfação do avaliador, todas apresentando valor abaixo da média ideal de satisfação; como pode ser observado no Gráfico 1.

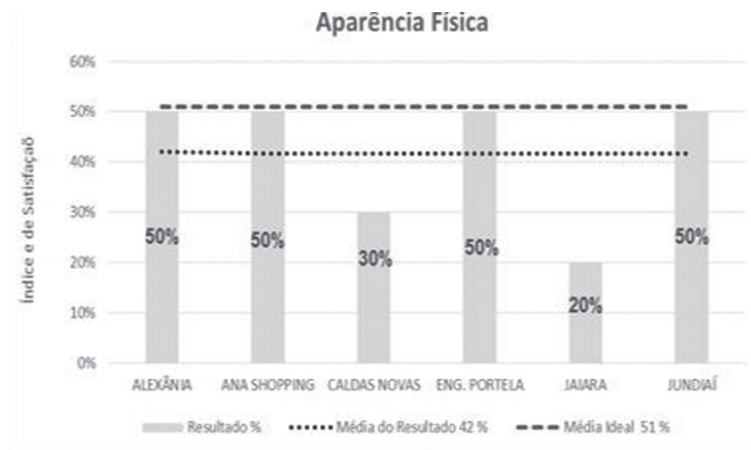

Gráfico 1. Índice de Satisfação - Aparência Física

Todas as lojas ficaram não conformes, referente ao item de identificação dos produtos expostos. Na loja da Jaiara, o único item conforme foi referente à limpeza, organização e conservação dos equipamentos e mobiliários.

Em termos de apresentação pessoal, os atendentes das lojas de Alexânia e Caldas Novas não estavam seguindo o recomendado quanto ao uso do uniforme padrão.

O bloco seguinte, apresentado pelo Gráfico 2, consolidou a mensuração dos dados relacionados ao Atendimento. Neste item, pode-se observar que a maioria das lojas ultrapassaram significativamente o índice ideal de satisfação de $51 \%$, sendo a média do resultado calculada em $78 \%$.

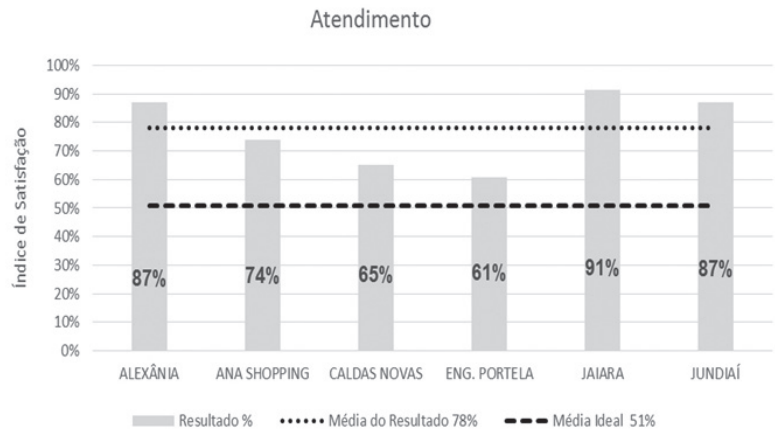

Gráfico 2: Índice de Satisfação - Atendimento

A loja Eng. Portela deparou-se com problemas quanto à abordagem, saudação ao consumidor, que permitiu uma pontuação relativamente menor às demais, o que resultou no índice de satisfação de $61 \%$, apresentado pela loja.

A loja da Jaiara foi a única que praticou a venda adicional.

No Gráfico 3, referente ao Fechamento da Venda, observou-se que as lojas estão com média de resultado em $34 \%$, ou seja, muito inferior ao índice ideal de $51 \%$.

Esse baixo índice de $34 \%$ é justificado pela quebra do fluxo em não entregar a comanda, pela falta de validação com o cliente dos produtos consumidos, pela não entrega espontânea do cupom fiscal e falta de coordenação e cooperação do trabalho em equipe entre os atendentes.

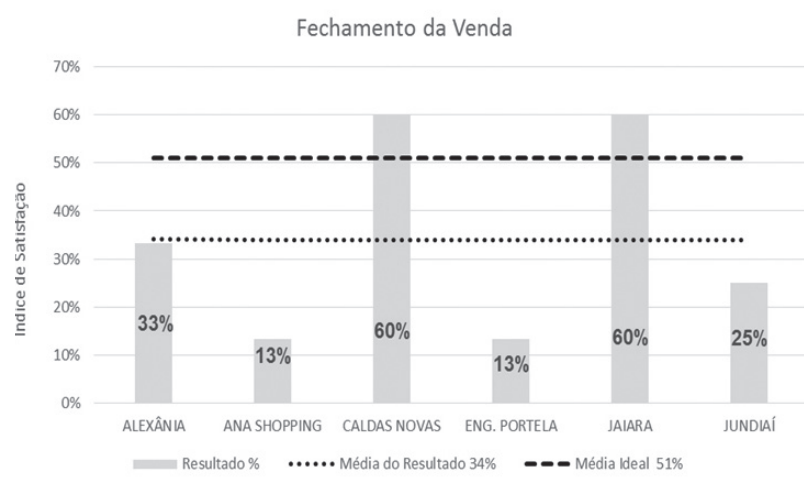

Gráfico 3. Índice de Satisfação - Fechamento da Venda 
O último item da avaliação do questionário, referente à Experiência de Compra, representado pelo Gráfico 4, avaliou a qualidade do produto e a satisfação perante a experiência de compra de um modo geral.

Ao analisar o Gráfico 4, observou-se que a média de $36 \%$ corresponde à satisfação do Cliente Oculto, perante a avaliação relacionada à percepção geral de qualidade, quanto aos produtos adquiridos, a experiência de compra e a indicação a conhecidos. Assim, é um índice considerado aceitável dentro do intervalo de $26 \%$ a $50 \%$, a qual foi estabelecida na metodologia.

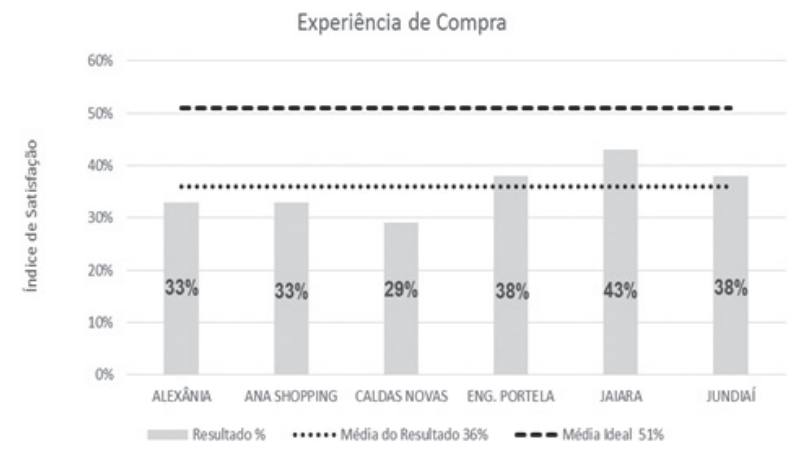

Gráfico 4: Índice de Satisfação - Experiência de Compra

Significando que, para as lojas serem consideradas ideais, o índice deveria estar acima de 51\%. Portanto, $36 \%$ representam uma satisfação aceitável como qualquer outra loja do ramo.

\section{Conclusão}

Esta técnica apresentou-se viável, pois possibilitou analisar de forma analítica os quesitos solicitados pela empresa. Avaliando de forma quantitativa o índice de satisfação desde a estrutura física até o fechamento da venda. Apresentando para a empresa, por meio das observações relatadas pelos avaliadores (Clientes Ocultos), os seguintes pontos para melhoria:

- Padronização do uso completo do uniforme;

- Planejamento da distribuição dos produtos para as lojas e franquias, principalmente, as localizadas em outras cidades, a fim de manter a qualidade e variedade dos produtos oferecidos;
- Promover treinamentos referentes à abordagem ao cliente e instrução aos colaboradores sobre a importância da entrega do cupom fiscal;

- Disponibilidade de o atendente servir o cliente a mesa, para não aguardar no balcão enquanto o produto é aquecido.

- Incentivo à prática da venda adicional de produtos e apresentação das campanhas promocionais vigentes, pelos atendentes;

- Oferta espontânea de degustação dos produtos em todas as lojas, como forma de atrair e aproximar o cliente.

Desta forma, esta técnica de marketing prestou com o seu objetivo de demonstrar efetivamente a qualidade na prestação de serviço em relação ao consumidor em todos os momentos do atendimento e a sua percepção quanto à estrutura física da loja.

\section{Referências}

1. Coutinho, L.; Ferraz, J.C. Estudo da Competitividade da indústria brasileira. Campinas, SP, Papirus. 1995. p. 510.

2. Schreiber, D. (Org.). Inovação e Aprendizagem Organização. Recurso Eletrônico. Novo Hamburgo: Feevale. 2013. 835 p.

3. Englert, N.F. Cliente Oculto: Análise do processo de coleta, entrega e utilização das informações obtidas na melhoria do atendimento no varejo. Trabalho de Conclusão de Curso (Graduação em Administração) - Departamento de Ciências Administrativas, Universidade Federal do Rio Grande do Sul, Porto Alegre, 2011.

4. Paladini, E.P.; Bridi, E. Gestão e Avaliação da Qualidade em Serviços para Organizações Competitivas. São Paulo: Editora Atlas, 2013. 241 p.

\section{Juliana C. Fernandes ${ }^{1 *}$, Sarah B. Lopes ${ }^{2}$ \& Suilly F. Bueno $^{3}$}

\author{
${ }^{1}$ Av. Anhanguera, Q. 91, L. 3, N 8.278, Apt. 02, Edifício Maria Alves \\ Corrêa, Setor Campinas, Goiânia- GO \\ ${ }^{2}$ Rua Minas Gerais, Q. 05, L. 06- B, Bairro Santa Luzia, Luziânia- GO \\ ${ }^{3}$ Rua Bela Vista, 275, Jardim Gonçalves, Anápolis- GO \\ *E-mail: correajf_@hotmail.com
}

